\title{
Structural Behavior of Concrete Filled Bamboo Columns Under Axial Loads
}

\author{
Shitabuleh Stephen* Sabuni Bernadette Kandie Bruce \\ Dept. of Civil Engineering, Masinde Muliro University of Science and Technology, Kenya
}

\begin{abstract}
This paper investigates the load carrying capacity development of concrete filled bamboo columns when subjected to static axial loads. Concrete Mix C20 and C30 were used to fill bamboo of different diameters and slenderness ratios. Compression tests were performed using Uniaxial Compression Machine under a loading rate of $31 \mathrm{Kn} / \mathrm{s}$. Results revealed that increase in concrete grade had significant effect on the carrying capacity and crushing stresses with $\mathrm{C} 20$ increasing the load capacity of concrete filled bamboo by 0.8 times while C30 by 1.5 times. The carrying capacity increases as the diameter of the column is increased but decreases as the slenderness ratio is increased due to reduced stiffness of the column. Increase in column diameter reduces the crushing stresses due to increased carrying area. Deformation behavior showed that specimens filled with concrete mix C20 are more ductile and undergoes large displacements before failure while C30 specimens showed brittleness characteristics in all samples.
\end{abstract}

Keywords: Bamboo. Concrete column, Ductility, Buckling, Deformation, Ultimate failure.

DOI: $10.7176 / \mathrm{CER} / 12-8-05$

Publication date:August $31^{\text {st }} 2020$

\section{Introduction}

In concrete filled Bamboo (CFB) specimens, plain concrete is used to fill the inside space of bamboo with the existence of exterior bamboo not only bearing a portion of axial load but also most importantly providing confinement to the infill concrete. Some temporary and permanent structures have incorporated bamboo as the main structural material due to its mechanical properties which are similar to timber. Bamboo mechanical properties have been studied by various researchers (Alito M ,2005; Lakkad and Patel 1981; Amada and sun, 2001;) through experimental and analytical research and concluded that it has a high tensile loading due to its tensile strength which is between $100 \mathrm{MPa}-400 \mathrm{MPa}$. This makes it a better alternative to steel when used as a reinforcement in structural steel. L. Gyansah et al, studied the fracture behaviour and crushing strength of bamboo under uniaxial loading conditions. They found the crushing stresses for fresh bamboo to be 51.3,71.1.74.5,79.5 and 85.2 MPa for the heights of 250,210,170,130 and $90 \mathrm{~mm}$ revealing the strength of bamboo being higher than other wooden structures. L.Gyansah and S.Kwofie presented also results of the effect of stress concentration on bamboo performance using un-notched and notched specimen. Crushing time was significantly affected by the variation in the notched angles .A notched angle of $20,30,60,80$ and $90^{\circ}$ had a $42.46,35.78,21.89,18.02$ and 10.30 as a crushing load an indication of time of failure of bamboo increases with decreasing notched angle.

Plain concrete is adopted in this research to be used as reinforcement in bamboo due to its distinguished properties such as high level of compressive strength and durability.(Neville 2011). The resulting material is thus a composite material with identifiable components to take advantage of the good characteristics of both constituents. Concrete is made up of the binder (Cement paste) and filler (coarse and fine aggregate) in which the filler is glued together by the binder to form synthetic conglomerate. The strength of concrete is determined by the proportions of each ingredients (gravel, sand, water and cement) (Churdley.R 1994). However concrete despite several advantages, has other limitations such as low ductility, low tensile strength, susceptible to cracking and low strength to weight ratio (Swamy,R.N. 2000)

Preliminary tests by Muhamad et al., (2017) suggested using foamcrete to fill conventional bamboo as a modification on raw bamboo to reduce timber usage in construction. The theoretical analysis implied an interaction between the foam crete and bamboo and corresponding increase in strength of the composite elements. Foam concrete is a light weight, free flowing material which is manufactured by ackling foam, prepared by aerating a foaming agent solution, to concrete mortar Bamboo of average diameter $100-150 \mathrm{~mm}$ and thickness $10-15 \mathrm{~mm}$ was used. A total of 16 samples was used in the research. The mix design for foamed concrete was adopted from the existing mix design with a density between $700-1000 \mathrm{~kg} / \mathrm{m}^{3}$ that had the optimum weight to strength ratio.

Table 1.1 Specimens strength of Foam Crete Filled bamboo (Muhamad et al.,2017)

\begin{tabular}{|l|l|l|l|l|}
\hline Samples & FCIB 1 & FCIB 2 & FCIB 3 & AVERAGE \\
\hline Compression(N/mm2) & 6.6 & 9.7 & 10.0 & 8.8 \\
\hline Flexural (N/mm2) & 4.5 & 4.2 & 3.8 & 4.2 \\
\hline Tensile (N/mm2) & 0.5 & 0.4 & 0.4 & 0.4 \\
\hline
\end{tabular}


The results showed an improvement of mechanical properties as shown in Table 1.1 indicating a substantial enhancement in strength when combined with other material.

L Gyansah and A. M Abd (2015)[11] conducted tests on raw bamboo reinforced with concrete to study their deformation behaviour and mechanical properties when subjected to concentric axial loads. Fresh bamboos were cut into the needed lengths such as $250 \mathrm{~mm}, 210 \mathrm{~mm}, 170 \mathrm{~mm}, 130 \mathrm{~mm}$ and 90 (i.e. interval of $40 \mathrm{~mm}$ ). The bamboo samples were then filled with concrete paste of ratio 1:3:6 and allowed for a week to dry and then crushed in compressive testing machine with maximum loading capacity of $1500 \mathrm{kN}$ to know the compressive load. The tests results revealed an increase of the compressive strength by $80 \%$ with both high ductility and low dilation capacity. This shows bamboo filled concrete is a viable alternative material that can be adopted as structural column in low load structures. However there's limited information on the performance of this material in terms of the ultimate carrying capacity when different grades of concrete are used with varying slenderness ratio. This study is carried to fill the gap in literature. The gain in axial strength and deformation characteristics are investigated bamboo when filled with concrete and subjected to uni-axial compressive loading, for the purposes of reliability and design.

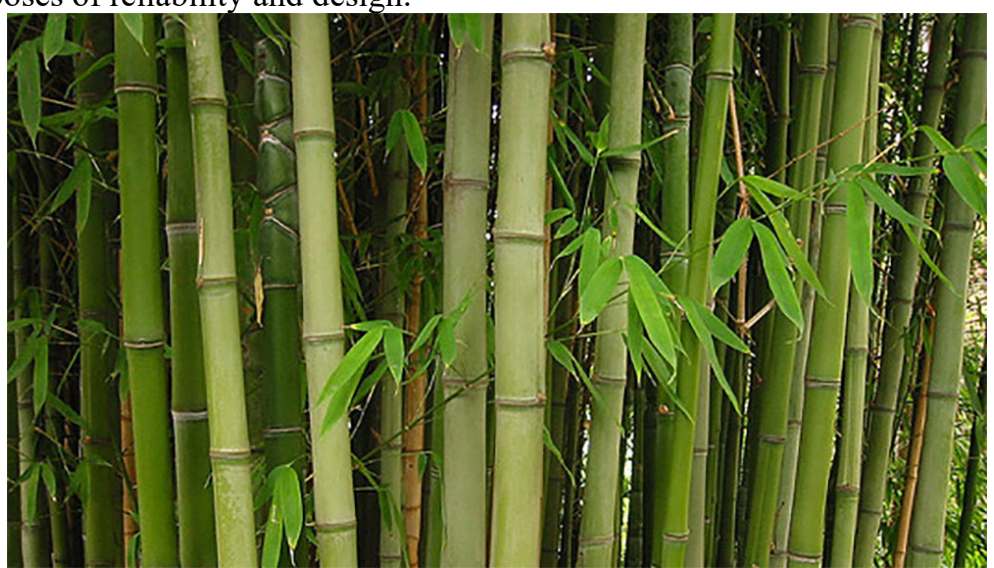

Figure 1 Bamboo grass

\section{Materials and methods}

\subsection{Materials}

Bambusa vulgaris is the bamboo specie used in this research as it is the most commonly available. The reinforcement concrete materials within bamboo consisted of coarse aggregates, fine aggregates, cement and water measured in the right proportions. The sand used as fine aggregate was able to pass through a $5 \mathrm{~mm}$ sieve whereas the coarse aggregate was also graded using sieve complying to BS 410:1976, the methods of test being outlined in BS 812: part 1:1975. Cement used was pozzolanic of class 32.5 Table 2.1 shows the mix proportions

Table 2.1 Summary of concrete mix proportions

\begin{tabular}{llllllll}
\hline $\begin{array}{l}\text { Concrete } \\
\text { mix }\end{array}$ & $\begin{array}{l}\text { Water/cement } \\
\text { ratio }\end{array}$ & $\begin{array}{l}\text { Water } \\
(\mathrm{kg} / \mathrm{m} 3)\end{array}$ & $\begin{array}{l}\text { Sand } \\
(\mathrm{kg} / \mathrm{m} 3)\end{array}$ & $\begin{array}{l}\text { cement } \\
(\mathrm{kg} / \mathrm{m} 3)\end{array}$ & $\begin{array}{l}\text { Aggregate } \\
(\mathrm{kg} / \mathrm{m} 3) \\
1 / 4\end{array}$ & $\begin{array}{l}\text { Compressive } \\
\text { Strength }\end{array}$ & $\begin{array}{l}\text { 28days }(\mathrm{MPa}) \\
\text { at }\end{array}$ \\
\hline C20 & 0.80 & 210.95 & 595 & 252 & 405 & 810 & 20.3 \\
\hline C 30 & 0.72 & 204.7 & 570 & 272 & 360 & 750 & 30.5 \\
\hline
\end{tabular}

\subsection{Sample preparation}

Fresh bamboos free from deformations of diameters 55, 75 and $100 \mathrm{~mm}$ were sourced from the forest, dried for three weeks and cut into needed slenderness ratios of 2,3 and 4 for each diameter. Specimens were carefully cut such that the node lies at the center of the culm height. They were then filled with predesigned concrete mix in layers, compacted by tamping rod and allowed to harden then placed in the water tank for 28 day curing. At the same time, concrete cubes were cast to determine the characteristic strength of the mix.

\subsection{Compression test}

Both the conventional bamboo and concrete filled bamboo specimens were placed on the lower platen of the UTM machine for compression. A loading rate of $31 \mathrm{kN} / \mathrm{s}$ was applied and specimens crushed to know the compressive load as shown in figure. Column behaviour was monitored and testing stopped when specimen could not resist more external load. 


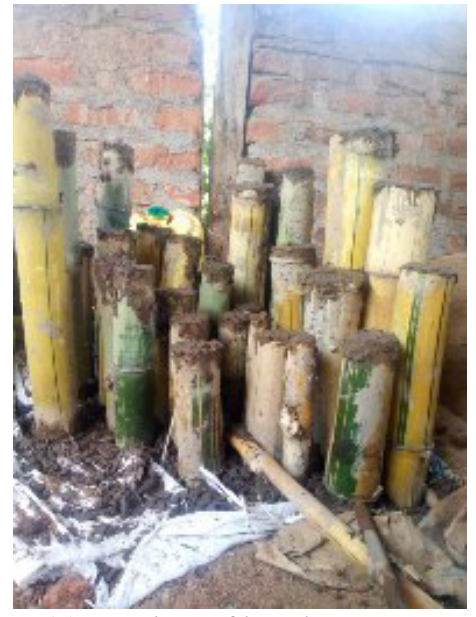

Fig 2(a) Casting of bamboo

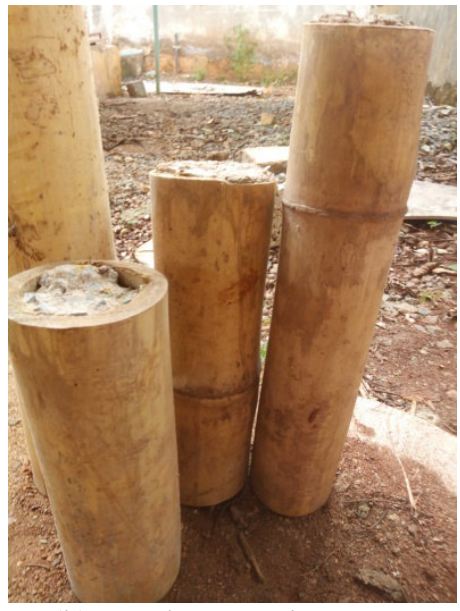

(b) Bamboo specimens

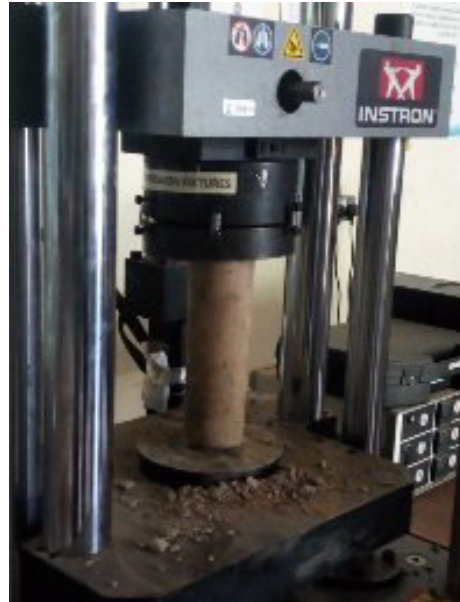

(c) Specimen in UTM

\subsection{Results and Discussions}

\subsection{Test Observation}

There was more less same behaviour observed in all specimens during the loading process. In the early loading stages, sounds were heard which may be due to concrete micro cracking followed by splitting and bursting of bamboo culm form the middle. For specimens filled with concrete mix C20, failure was sudden and concrete completely pulverized as shown in figure 3.1(a). In some specimens, composite column failure was observed after cracking of the bamboo at the nodes. For concrete filled with concrete mix $\mathrm{C} 30$ (fig $3 \mathrm{~b}$ ), there was no obvious transverse displacement and deformation phenomena observed on the composite columns before the ultimate load was reached. All of the columns lost their load-bearing capacity during the post peak loading process, thereby suggesting that all failure modes were' due to buckling.

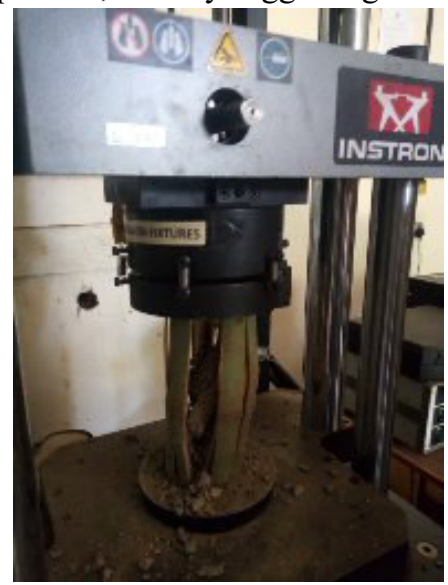

Fig 3.1 (a)Mix C20 failure

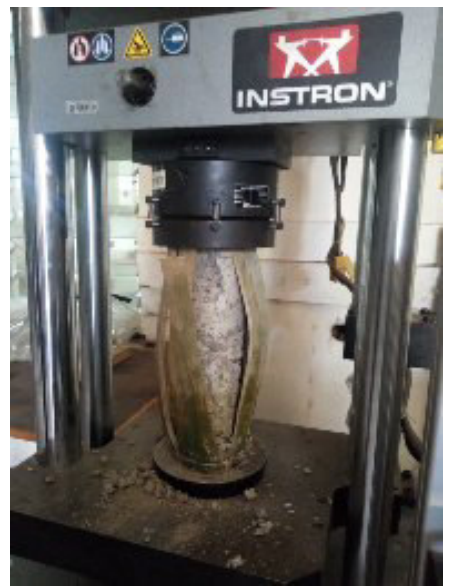

(b) Mix C30 failure

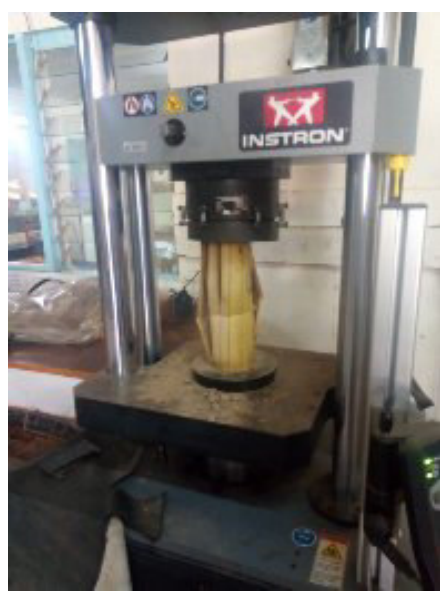

(c) Raw bamboo

3.2 Concrete grade and slenderness ratio effect on the load carrying capacity.

Figures 3.2 to 3.4 show results of varying concrete grade and slenderness ratio on load capacity and crushing stresses. 


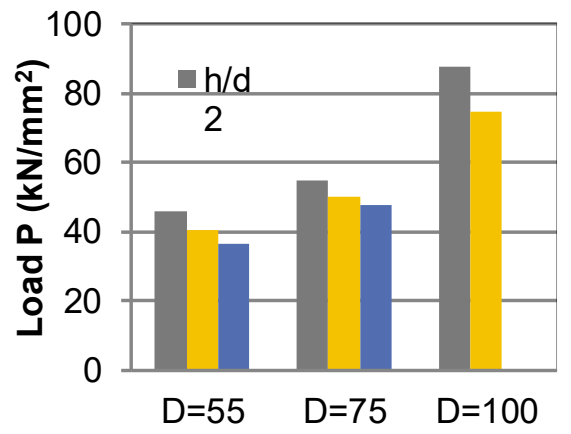

Diameter $(\mathrm{mm})$

Figure 3.2 Concrete mix C20 strength and load variation for Bamboo Filled Concrete

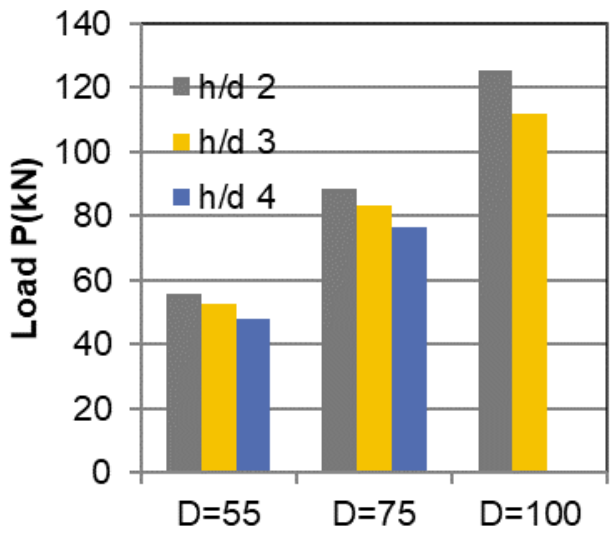

Diameter $(\mathbf{m m})$

$\begin{array}{cc}\text { Diameter }(\mathbf{m m}) & \text { Diameter }(\mathbf{m m}) \\ \text { Figure 3.3 Concrete mix C30 Load and strength variation for Bamboo Filled Concrete }\end{array}$

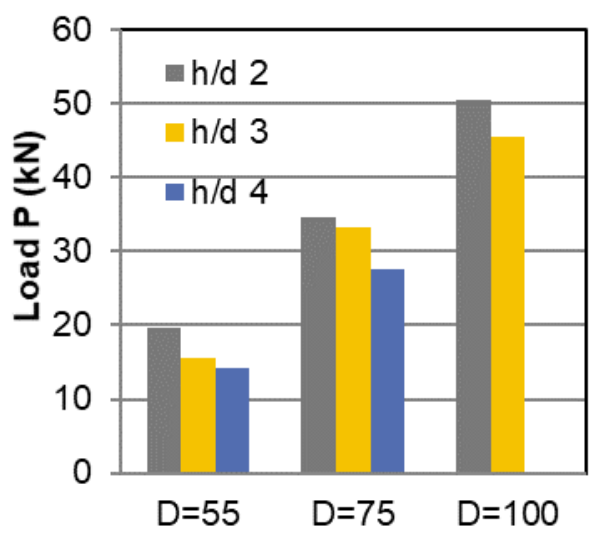

Diameter (mm)

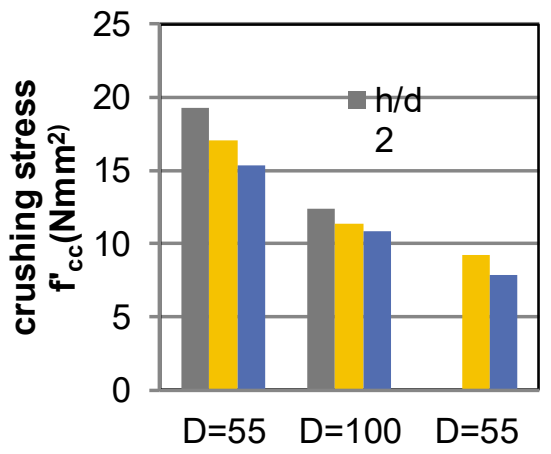

Diameter (mm)

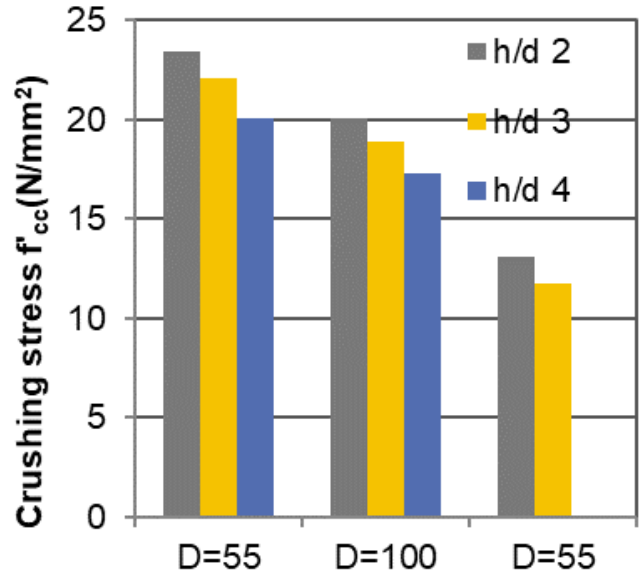

Diameter $(\mathbf{m m})$
oo Filled Concrete

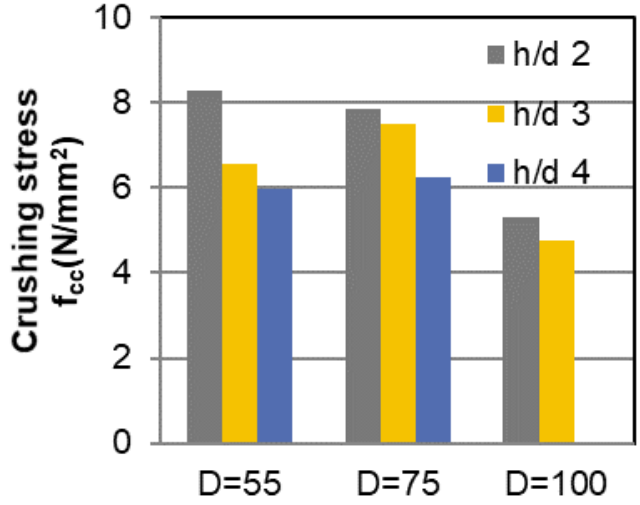

Diameter (mm)

Figure 3.4 Concrete mix C30 Load and strength variation for Bamboo Filled Concrete

Observation shows bamboo specimens filled with concrete has significant strength improvements depending on the grade of the infilled concrete. The load capacity of bamboo filled with concrete of grade C20 is averagely increased by 0.8 times in most of the specimens regardless of the diameter and slenderness ratio while grade C30 increases the load carrying capacity by 1.5 and this is due to increased elastic modulus of concrete. Results further indicate that increase in diameter of the column increases the load capacity in columns cast with the same concrete grade and this can be attributed to increased carrying area.. However there's decrease in load carrying capacity as the slenderness ratio of the columns is increased. This is due to column stiffness reducing as slenderness ratio is increased. As opposed to short columns failure due to buckling is more pronounced in slender columns due to reduced stiffness and increased height, though the variation in this research is small as maximum slenderness is 4 and hence all columns can be considered to be short. When 
diameter of the column is increased the height is also increased for the slenderness ratio to be kept constant. For same slenderness ratio smaller diameter columns are short compared to larger diameter columns. This explains why when the diameter of the column is reduced from $100 \mathrm{~mm}$ to $55 \mathrm{~mm}$ while the crushing stresses is increased in all specimens.

\subsection{Loads-deformation characteristics}

Figures $3.5 \mathrm{a}$ and $3.5 \mathrm{~b}$ are the curves of load-deformation for Concrete filled bamboo columns.

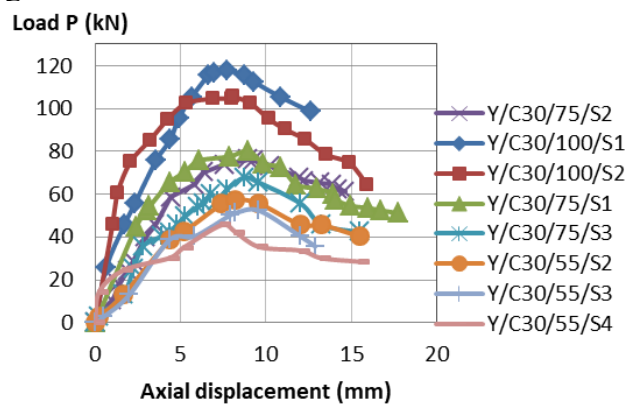

Fig.3.5a) Concrete grade C 30

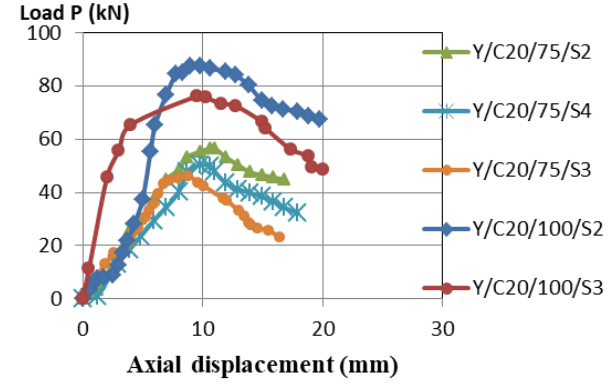

b) Concrete grade $\mathrm{C} 20$

Large diameter specimens with small slenderness ratio resist high loads due to great energy dissipating behaviour than those with small diameter as it can be seen from the figures. At the beginning all specimens showed an elastic range followed by a plastic range which resulted in permanent deformation. Upon unloading a softer reloading curve than initial loading curve was shown in all specimens with recovery of initial stiffness upon exceeding the maximum load. The failure was generally soft with capacity degrading slowly after the longitudinal splitting has occurred and the ultimate load has been reached reflecting the dominance effect of the nodes. Raw bamboo generally fails at very low loads than when filled with concrete due to combining effects of both bamboo and concrete. Composite columns with low strength concrete undergoes large deformation before the ultimate load capacity is reached as observed from the figures. The elastic modulus and consequently stiffness is low for low strength concrete making it more flexible thus interacting effectively with the culm, consequently increasing the composite action since it is able to flow. Figure 4.8 and 4.10 shows post peak behaviour is affected significantly by the concrete strength.

As the concrete grade increases for composite columns filled with different characteristic strengths, the sloping curve becomes steeper when diameter is constant. Concrete becomes more brittle with increase in characteristic strength hence the increase in absolute values of the curve. The residual specimen strength increases with decrease in strength of concrete substantiating further the higher ductility claim of lower concrete strength. The columns energy absorption capacity is represented by the area under the load deformation curves. It follows that concrete with lower characteristic strength has a high energy absorption capacity as well as high ductility. Increase in column diameter increases the ductility hence the higher energy absorption. Peak load is attained fast in composite columns filled with high strength concrete

\section{Conclusions}

In this paper, load carrying capacity ductility and deformation characteristics of bamboo filled with concrete grade $\mathrm{C} 20$ and $\mathrm{C} 30$ is investigated. The following conclusions have been drawn from the study

1) Concrete grade $\mathrm{C} 30$ increased the carrying capacity of bamboo by 1.5 times while grade $\mathrm{C} 20$ increased the capacity by 0.8 times.

2) The load capacity increases as the diameter of the columns is increased for the same concrete grade. However the capacity reduces as the slenderness ratio is increased due to reduced stiffness in the column for all concrete grades.

3) The presence of infill concrete not only delayed the buckling but prevented bamboo from buckling inwards of bamboo column. This depends on the strength of concrete.

4) Bamboo filled with concrete of grade 20 experienced large deformations before failure, signifying a higher ductility behaviour than bamboo filled with concrete grade C30

The study therefore concludes that concrete not only delays the buckling of bamboo but also improves significantly the load carrying capacity and ductility depending on the grade used to fill bamboo.

\section{Acknowledgement}

Authors are also thankful to the laboratory assistants of Masinde Muliro University of Science and Technology Department of civil engineering Kenya 


\section{References}

L. Gyansah, A.S. Akinwonmi and M. Affam, The Fracture Behaviour of Fresh Bamboo Under Uniaxial Compressive Loading Condition. Research Journal of Applied Sciences, Engineering and Technology, 2(8): , (2010), 720-726.

L. Gyansah and S. Kwofie, "Investigation into the Performance of Bamboo Using the Notched and the UnNotched Specimen". Research Journal of Applied Sciences, Engineering and Technology, 3(04): (2011), 245-251.

Chudley, R., “ concrete”, Construction Technology”, Second SI Edition, ELBS with Longman (Publishers) Ltd, Vol. 1, (1994), pp. 20-24.

Swamy, R.N., "Sustainable concrete for Infrastructure Regeneration and Reconstruction", International Conference on Sustainable Construction into the next Millennium Environmentally friendly and innovative Cement Based Materials, Joao Pessoa, Brazil, (2000), pp. 15-44.

Neville, A. M., (2011). “Properties of Concrete.”5th Edition. ISBN 978-0-27375580-7, Prentice Hall, Pearson Education Ltd, England.

Muhamad Azani Yahya and Mohamed Alias Yusof (2017) 'Preliminary Study on Foam Concrete Infill Bamboo as Construction Materials, journal of Engineering and Applied Sciences 12 (16): 4063-4067, 2017

L.Gyansah and A. M. Abd El-Aty "Experimental study of the deformation behaviour and mechanical properties of fresh reinforced bamboo" Advanced Materials Research ISSN: 1662-8985, (2015) Vol. 1102, pp 173182

Xiaobo Li. (2004). Physical, Chemical and mechanical Properties of Bamboo and its Utilization Potential for Fiberboard manufacturing. Masters 'Thesis. Louisiana State University and Agricultural and

Alito M. (2005). 'Bamboo Reinforcement as Structural Material for the Construction of Low-Cost Houses in Ethiopia'. Master thesis, Addis Ababa University, Ethiopia.

Lakkad, S. and Patel, J.M. "Mechanical Properties of bamboo, a natural composite", Fiber Science Technology, Vol. 14, (1980), pp. 319 - 322.

Amada, S. and Untao, S. (2001), “Fracture Properties of Bamboo”, Composites Part B. Vol. 32, pp 451-459. 